\title{
Influence of age on the diagnostic accuracy of soluble biomarkers for tuberculous pleural effusion: a post hoc analysis
}

\author{
Chun-Guo Jiang ${ }^{1}$, Wen Wang ${ }^{1}$, Qiong Zhou ${ }^{2}$, Xiu-Zhi Wu' ${ }^{1}$, Xiao-Juan Wang ${ }^{1}$, Zhen Wang ${ }^{1}$, Kan Zhai ${ }^{1}$ and \\ Huan-Zhong Shi ${ }^{*}$
}

\begin{abstract}
Background: Accurately diagnosing pleural effusion is a frequent and significant problem in clinical practice. Combining pleural biomarkers with patients' age may be a valuable method for diagnosing TPE. We sought to evaluate the influence of age on diagnostic values of pleural adenosine deaminase (ADA), interferon-gamma (IFN- $\gamma$ ), and interleukin 27 (IL-27) for tuberculous pleural effusion (TPE).

Methods: Two hundred seventy-four consecutive adult patients with pleural effusion were selected from Beijing and Wuhan between January 1, 2014 and June 30, 2015, and their pleural fluid concentrations of ADA, IFN- $\gamma$, and IL-27 were tested. Biomarker performance was analyzed by standard receiver operating characteristic (ROC) curves according to different ages.

Results: Data from the Beijing cohort showed that ADA, IFN- $\gamma$, and IL-27 could all accurately diagnose TPE in young patients ( $\leq 40$ years of age). With a cutoff of $21.4 \mathrm{U} / \mathrm{L}$, the area under the curve (AUC), sensitivity, specificity, positive predictive value (PPV), and negative predictive value (NPV) of ADA for diagnosing TPE were 1.000 (95\% confidence interval: 0.884-1.000), 100.0, 100.0\%, 100.0, and 100.0, respectively. In older patients (> 40 years of age), IL-27 and IFN- $\gamma$ were excellent biomarkers for discriminating TPE versus non-TPE cases. With a cutoff of $591.4 \mathrm{ng} / \mathrm{L}$, the AUC, sensitivity, specificity, PPV, and NPV of IL-27 for diagnosing TPE were 0.976 (95\% confidence interval: 0.932-0.995), 96.3, 99.0\%, 96.3, and 99.0, respectively. Similar diagnostic accuracy among the three pleural biomarkers was validated in the Wuhan cohort.
\end{abstract}

Conclusions: Among young patients, ADA is reliable for diagnosing TPE. Conversely, in older patients, IL-27 and IFN- $\gamma$ are excellent biomarkers to differentiate TPE versus non-TPE cases.

Keywords: Adenosine deaminase, Interferon-gamma, Interleukin 27, Tuberculous pleural effusion

\footnotetext{
* Correspondence: shihuanzhong@sina.com

'Department of Respiratory and Critical Care Medicine, Beijing Chaoyang Hospital, Capital Medical University, 8 Gongti Nanlu, Chaoyang District, Beijing 100020, China

Full list of author information is available at the end of the article
}

(c) The Author(s). 2020 Open Access This article is licensed under a Creative Commons Attribution 4.0 International License, which permits use, sharing, adaptation, distribution and reproduction in any medium or format, as long as you give appropriate credit to the original author(s) and the source, provide a link to the Creative Commons licence, and indicate if changes were made. The images or other third party material in this article are included in the article's Creative Commons licence, unless indicated otherwise in a credit line to the material. If material is not included in the article's Creative Commons licence and your intended use is not permitted by statutory regulation or exceeds the permitted use, you will need to obtain permission directly from the copyright holder. To view a copy of this licence, visit http://creativecommons.org/licenses/by/4.0/. The Creative Commons Public Domain Dedication waiver (http://creativecommons.org/publicdomain/zero/1.0/) applies to the data made available in this article, unless otherwise stated in a credit line to the data. 


\section{Background}

Tuberculosis is a serious public health problem globally but especially in developing countries. Tuberculous pleural effusion (TPE) ranks among the most regular forms of extrapulmonary tuberculosis [1]. The definitive diagnosis of TPE relies upon the presence of Mycobacterium tuberculosis in the sputum, pleural effusion, or pleural biopsy specimens [2]. To achieve the gold standard, conventional diagnostic tests include microscopic examination and/or culturing of pleural fluid, sputum, or pleural tissue for acid-fast bacilli or the histopathological demonstration of caseating granulomas in the pleura along with acid-fast bacilli. These tests have recognized limitations in clinical practice, such as low sensitivity, lengthy delay, or invasiveness [3, 4]; as a result, multiple biomarkers in pleural effusion have been investigated, including adenosine deaminase (ADA) and interferon-gamma (IFN- $\gamma$ ) [5].

Differences in the diagnostic value of the same biomarker in the literature is associated with a variety of factors. One such factor is age, which has been reported to be correlated with pleural ADA levels and affects the diagnostic accuracy of TPE [6-11]. One possible explanation is that elderly people suffer a degradation of immune status with aging, believed to result from a functional decrease in lymphocyte and macrophage levels [10], and this may affect the levels of pleural biomarkers. However, it is still less clear as to whether combining pleural biomarkers with patients' age could be a valuable method for estimating the probability of TPE.

We conducted two prospective studies and one metaanalysis, finding that the diagnostic value of interleukin 27 (IL-27) is comparable to that of IFN- $\gamma$ and more accurate than that of ADA [12]. Through a post-hoc analysis of the two independent prospective blind studies, we focused on the influence of age, as an independent covariate, on the diagnostic accuracy of ADA, IFN- $\gamma$, and IL-27 in pleural fluid to differentiate between TPE and non-TPE cases.

\section{Methods}

Study populations, diagnostic criteria, sample collection, and determination

As previously described [12], our cohort included 154 consecutively enrolled adult patients ( $\geq 18$ years old) from Beijing Chaoyang Hospital (Beijing cohort) and 120 consecutively enrolled patients from Union Hospital, Tongji Medical College (Wuhan cohort). Enrollment occurred between January 1, 2014 and June 30, 2015. Approvals were granted for the conduct of this study by the appropriate ethics committees (No. 2012-S068, 2014-ke-63). Based on the established criteria, cases were classified as either TPE, malignant pleural effusion (MPE), parapneumonic pleural effusion (PPE), and miscellaneous pleural effusion [12]. Pleural fluid was obtained by the first successful thoracentesis before treatment initiation and was measured using colorimetric method kits for ADA activity and enzyme-linked immunosorbent assay kits for IFN- $\gamma$ and IL-27. The technicians performing the assays were unaware of the nature of the samples, and the statisticians broke the code to analyze the database.

\section{Statistical analysis}

Data are presented as means \pm standard errors of the means or medians with 25 th and 75 th percentiles, depending on normal distribution by the KolmogorovSmirnov test. For group comparisons, the Student's $t$ test, Mann-Whitney $U$ test, one-way analysis of variance (ANOVA), or Kruskal-Wallis ANOVA on ranks were used. Receiver operating characteristic (ROC) curves were drawn to evaluate the diagnostic performance of the three biomarkers in pleural effusion. Areas under the curves (AUCs) were computed and compared using the Hanley and McNeil procedure [13], including sensitivity, specificity, positive and negative likelihood ratios (PLR and NLR), and positive and negative predictive values (PPV and NPV) [14]. The parameters of diagnostic accuracy are shown together with their 95\% confidence intervals (CIs). ROCs of the same tests in independent populations were compared by using the method proposed by Gönen M [15].

The optimal cutoff values of ADA, IFN- $\gamma$, and IL-27 obtained in the Beijing cohort were $21.4 \mathrm{U} / \mathrm{L}, 116.1 \mathrm{ng} / \mathrm{L}$, and $591.4 \mathrm{ng} / \mathrm{L}$, respectively, and these were verified in the Wuhan cohort [12]. In the present study, to determine the diagnostic accuracy of each biomarker in different ages separately, cases complying with the cutoff values were considered as positive. The data were analyzed using the Statistical Package for the Social Sciences (IBM Corp., Armonk, NY, USA) and MedCalc software (MedCalc Software, Ostend, Belgium) and $p<0.05$ was considered statistically significant.

\section{Results \\ Clinical characteristics}

The baseline characteristics of the 274 patients recruited in both cohorts are summarized in Table 1. According to previous literatures $[16,17]$ and our preliminary statistics, we selected 40 years old as the cut point for two age groups: young patients ( $\geq 18$ years to 40 years of age) and older patients ( $>40$ years of age). In both cohorts, as compared with older patients, the prevalence of TPE was relatively high ( $80 \%$ in Beijing and $70 \%$ in Wuhan) in young patients. There were no differences in demographic characteristics between the Beijing and Wuhan cohorts. 
Table 1 Demographic characteristics ${ }^{a}$

\begin{tabular}{|c|c|c|c|c|c|c|c|c|c|}
\hline & \multirow[b]{2}{*}{ Variable } & \multicolumn{4}{|c|}{ Beijing cohort } & \multicolumn{4}{|c|}{ Wuhan cohort } \\
\hline & & TPE & MPE & PPE & Miscellaneous & TPE & MPE & PPE & Miscellaneous \\
\hline \multirow[t]{3}{*}{$\leq 40$} & $n$ & 24 & 3 & 1 & 2 & 14 & 3 & 2 & 1 \\
\hline & Sex, male, \% & 62.5 & 0 & 100 & 50 & 85.7 & 100 & 100 & 0 \\
\hline & Age, years & $26.7 \pm 1.2$ & $37.7 \pm 1.9$ & 25 & $28.5 \pm 3.5$ & $29.2 \pm 2.1$ & $36.7 \pm 2.8$ & $35.5 \pm 0.5$ & 28 \\
\hline \multirow[t]{3}{*}{$>40$} & $n$ & 27 & 58 & 27 & 12 & 30 & 44 & 17 & 9 \\
\hline & Sex, male, \% & 66.7 & 60.3 & 85.2 & 91.7 & 70 & 52.3 & 76.5 & 55.6 \\
\hline & Age, years & $57.9 \pm 2.5$ & $64.5 \pm 1.4$ & $62.9 \pm 2.0$ & $67.3 \pm 3.2$ & $57.4 \pm 2.4$ & $60.0 \pm 1.3$ & $65.3 \pm 3.3$ & $57.6 \pm 3.6$ \\
\hline
\end{tabular}

${ }^{\mathrm{a}}$ Data are presented as means \pm SEMs. MPE malignant pleural effusion; PPE parapneumonic pleural effusion; TPE tuberculous pleural effusion

\section{ADA, IFN- - , and IL-27 concentrations}

Regardless of age, the concentrations of ADA, IFN- $\gamma$, and IL-27 in TPE patients were all significantly higher than those in non-TPE patients in each cohort and in the combined population (all $p<0.001$ ) (Table 2), and no differences were found among MPE, PPE, or miscellaneous effusions (all $p>0.05$ ). We also noted that, either among all patients with pleural effusion or TPE patients, there was no difference in the concentrations of ADA, IFN- $\gamma$, or IL-27 between age groups in both cohorts (all p > 0.05).

\section{Diagnostic accuracy of ADA, IFN- $\gamma$, and IL-27 in the Beijing cohort}

The capacity of ADA, IFN- $\gamma$, and IL-27 to diagnose TPE was assessed using ROC curve analysis in the Beijing cohort (Table 3 and Fig. 1). In young patients, ADA, IFN- $\gamma$, and IL-27 all accurately discriminated TPE and non-TPE $(p<0.001)$. It's worth noting that, with a cutoff of $21.4 \mathrm{U} / \mathrm{L}$, the AUC of ADA in discriminating TPE from non-TPE was 1.000 (95\% CI: $0.884-1.000 ; \mathrm{p}<0.001)$, while the sensitivity, specificity, NLR, PPV, and NPV of ADA were 100.0, $100.0 \%, 0,100.0$, and 100.0, respectively. Meanwhile, the AUCs of IFN- $\gamma$ and IL-27 were 0.958 (95\% CI: $0.815-0.998$ ) and 0.979 (95\% CI: 0.848-1.000), respectively. Z-statistical analysis further revealed that the AUC $(95 \% \mathrm{CI})$ of ADA was not significantly different from that of IFN- $\gamma[0.042(-0.028$ to 0.112$)$; $\mathrm{Z}=1.167 ; p=0.243]$ or IL-27 [0.021 ( -0.028 to 0.070$)$; $\mathrm{z}=0.829 ; p=0.407]$.

In the subgroup of older patients, with a cutoff of $591.4 \mathrm{ng} / \mathrm{L}, \mathrm{IL}-27$ presented the largest AUC (95\% CI) [0.976 (0.932-0.995); $p<0.001]$ to differentiate TPE and non-TPE (Table 3 and Fig. 1). The sensitivity, specificity, PLR, NLR, PPV, and NPV of IL-27 were 96.3, 99.0\%, 93.4, 0, 96.3, and 99.0, respectively. The AUCs (95\% CIs) of ADA and IFN- $\gamma$ were $0.817(0.737-0.880)$ and 0.919 (0.856-0.960), respectively. The AUC (95\% CI) of IL-27 was much higher than that of ADA [0.160 (0.057$0.262) ; \mathrm{z}=3.048 ; p=0.002$ ] but not significantly higher than that of IFN- $\gamma[0.058(-0.027$ to 0.142$) ; \mathrm{z}=1.339$; $p=0.181]$.

The AUC of ADA in young patients was significantly higher than that in older patients $[0.183(0.083-0.283)$; $\mathrm{z}=3.594 ; p<0.001]$; however, there were no significant differences between young patients and older patients in terms of IFN- $\gamma[0.040(-0.062$ to 0.141$) ; \mathrm{z}=0.765 ; p=$

Table 2 Concentrations of ADA, IFN- $\gamma$, and IL-27 in pleural fluid according to study cohort and age*

\begin{tabular}{|c|c|c|c|c|c|c|c|c|c|c|c|c|c|}
\hline & & Beijing co & hort $(n=$ & 154) & & Wuhan c & hort $(n=$ & 120) & & Total $(n=$ & 274) & & \\
\hline & Variable & TPE & MPE & PPE & Miscellaneous & TPE & MPE & PPE & Miscellaneous & TPE & MPE & PPE & Miscellaneous \\
\hline$\leq 40$ & $\begin{array}{l}\text { ADA, } \\
U / L\end{array}$ & $\begin{array}{l}55.6 \pm \\
5.3 \dagger\end{array}$ & $\begin{array}{l}8.47 \pm \\
2.4\end{array}$ & 2.6 & $8.5 \pm 2.4$ & $\begin{array}{l}62.0 \pm \\
12.3 \dagger\end{array}$ & $\begin{array}{l}9.0 \pm \\
1.4\end{array}$ & $\begin{array}{l}14.1 \pm \\
2.4\end{array}$ & 21.0 & $\begin{array}{l}58.0 \pm \\
5.5 \dagger\end{array}$ & $\begin{array}{l}8.7 \pm \\
1.3\end{array}$ & $\begin{array}{l}10.2 \pm \\
4.1\end{array}$ & $9.8 \pm 3.2$ \\
\hline & $\begin{array}{l}\text { IFN- }{ }^{\prime} \text {, } \\
n g / L\end{array}$ & $\begin{array}{l}3407.1 \pm \\
736.2 \neq\end{array}$ & $\begin{array}{l}44.7 \pm \\
8.7\end{array}$ & 42.9 & $44.7 \pm 8.7$ & $\begin{array}{l}2297.5 \pm \\
543.0 \neq\end{array}$ & $\begin{array}{l}16.4 \pm \\
1.4\end{array}$ & $\begin{array}{l}14.8 \pm \\
0.8\end{array}$ & 104.7 & $\begin{array}{l}2998.2 \pm \\
508.6 \neq\end{array}$ & $\begin{array}{l}30.5 \pm \\
7.4\end{array}$ & $\begin{array}{l}24.2 \pm \\
9.4\end{array}$ & $49.6 \pm 9.7$ \\
\hline & $\begin{array}{l}\text { IL-27, } \\
n g / L\end{array}$ & $\begin{array}{l}875.8 \pm \\
51.3+\end{array}$ & $\begin{array}{l}279.0 \pm \\
24.9\end{array}$ & 198.2 & $279.0 \pm 24.9$ & $\begin{array}{l}853.8 \pm \\
49.8+\end{array}$ & $\begin{array}{l}240.4 \pm \\
37.7\end{array}$ & $\begin{array}{l}452.7 \pm \\
138.4\end{array}$ & 240.4 & $\begin{array}{l}867.7 \pm \\
36.9+\end{array}$ & $\begin{array}{l}259.7 \pm \\
22.0\end{array}$ & $\begin{array}{l}367.9 \pm \\
116.5\end{array}$ & $381.9 \pm 106.7$ \\
\hline$>40$ & $\begin{array}{l}\text { ADA, } \\
U / L\end{array}$ & $\begin{array}{l}43.5 \pm \\
4.9+\end{array}$ & $\begin{array}{l}16.0 \pm \\
1.4\end{array}$ & $\begin{array}{l}14.9 \pm \\
1.6\end{array}$ & $16.1 \pm 2.2$ & $\begin{array}{l}41.8 \pm \\
4.0 \dagger\end{array}$ & $\begin{array}{l}13.6 \pm \\
1.3\end{array}$ & $\begin{array}{l}14.7 \pm \\
1.3\end{array}$ & $18.3 \pm 2.2$ & $\begin{array}{l}42.7 \pm \\
4.4 \dagger\end{array}$ & $\begin{array}{l}14.8 \pm \\
1.3\end{array}$ & $\begin{array}{l}14.8 \pm \\
1.4\end{array}$ & $17.2 \pm 2.2$ \\
\hline & $\begin{array}{l}\text { IFN- }{ }^{\prime} \text {, } \\
n g / L\end{array}$ & $\begin{array}{l}2176.4 \pm \\
641.9 \neq\end{array}$ & $\begin{array}{l}35.7 \pm \\
3.3\end{array}$ & $\begin{array}{l}59.8 \pm \\
17.4\end{array}$ & $102.0 \pm 54.6$ & $\begin{array}{l}2508.5 \pm \\
660.5 \neq\end{array}$ & $\begin{array}{l}41.3 \pm \\
7.3\end{array}$ & $\begin{array}{l}67.3 \pm \\
10.5\end{array}$ & $111.9 \pm 63.5$ & $\begin{array}{l}2342.2 \pm \\
651.2 \ddagger\end{array}$ & $\begin{array}{l}38.5 \pm \\
5.2\end{array}$ & $\begin{array}{l}63.6 \pm \\
14.0\end{array}$ & $107.0 \pm 59.1$ \\
\hline & $\begin{array}{l}\text { IL-27, } \\
n g / L\end{array}$ & $\begin{array}{l}907.7 \pm \\
49.1 \dagger\end{array}$ & $\begin{array}{l}299.3 \pm \\
13.8\end{array}$ & $\begin{array}{l}273.1 \pm \\
16.5\end{array}$ & $251.7 \pm 14.1$ & $\begin{array}{l}900.0 \pm \\
52.9+\end{array}$ & $\begin{array}{l}292.0 \pm \\
13.5\end{array}$ & $\begin{array}{l}289.6 \pm \\
18.1\end{array}$ & $253.6 \pm 20.5$ & $\begin{array}{l}903.9 \pm \\
51.0 \dagger\end{array}$ & $\begin{array}{l}295.7 \pm \\
13.6\end{array}$ & $\begin{array}{l}281.3 \pm \\
17.3\end{array}$ & $252.7 \pm 17.3$ \\
\hline
\end{tabular}

*Data are presented as mean \pm SEM or median (25th - 75th centile). $+p<0.001$ compared with each non-TPE group using analysis of variance (ANOVA) followed by Bonferroni's test; $\neq \mathrm{p}<0.001$ compared with the corresponding serum using paired $t$ test. ADA, adenosine deaminase; IFN, interferon; IL, interleukin; MPE, malignant pleural effusion; PPE, parapneumonic pleural effusion; TPE, tuberculous pleural effusion 
Table 3 Diagnostic performance of pleural IL-27, ADA, and IFN- $\gamma$ in differentiating between patients with tuberculous pleural effusion (TPE) and those with non-TPEs in the Beijing cohort $(n=154)$

\begin{tabular}{|c|c|c|c|c|c|c|c|c|c|}
\hline Age & Variable & $\begin{array}{l}\text { Cut-off } \\
\text { value }\end{array}$ & AUC (95\% Cl) & Sensitivity (\%) & Specificity (\%) & PLR & NLR & PPV & NPV \\
\hline \multirow[t]{3}{*}{$\leq 40$} & ADA & $21.4 \mathrm{U} / \mathrm{L}$ & $\begin{array}{l}1.000(0.884 \text { to } \\
1.000)\end{array}$ & $\begin{array}{l}100.0 \text { (85.8 to } \\
100.0 \text { ) }\end{array}$ & $\begin{array}{l}100.0(54.1 \text { to } \\
100.0)\end{array}$ & - & 0 & 100.0 & 100.0 \\
\hline & $\mathrm{IFN}-\gamma$ & $116.1 \mathrm{ng} / \mathrm{L}$ & $\begin{array}{l}0.958 \text { ( } 0.815 \text { to } \\
0.998)\end{array}$ & $\begin{array}{l}91.7 \text { (73.0 to } \\
99.0)\end{array}$ & $\begin{array}{l}100.0 \text { (54.1 to } \\
100.0)\end{array}$ & - & $\begin{array}{l}0.1 \text { (0 to } \\
0.3 \text { ) }\end{array}$ & 100.0 & $\begin{array}{l}75.0 \text { (44.3 to } \\
91.9)\end{array}$ \\
\hline & IL-27 & $591.4 \mathrm{ng} / \mathrm{L}$ & $\begin{array}{l}0.979 \text { (0.848 to } \\
1.000)\end{array}$ & $\begin{array}{l}95.8 \text { (78.9 to } \\
99.9)\end{array}$ & $\begin{array}{l}100.0(54.1 \text { to } \\
100.0)\end{array}$ & - & 0 (0 to 0.3 ) & 100.0 & $\begin{array}{l}85.7 \text { (46.8 to } \\
97.6)\end{array}$ \\
\hline \multirow[t]{3}{*}{$>40$} & ADA & $21.4 \mathrm{U} / \mathrm{L}$ & $\begin{array}{l}0.817 \text { ( } 0.737 \text { to } \\
0.880 \text { ) }\end{array}$ & $\begin{array}{l}77.8(57.7 \text { to } \\
91.4)\end{array}$ & $\begin{array}{l}85.6 \text { (77.0 to } \\
91.9)\end{array}$ & 5.4 (3.2 to 9.1 ) & $\begin{array}{l}0.3 \text { ( } 0.1 \text { to } \\
0.5)\end{array}$ & $\begin{array}{l}60.0 \text { (47.0 to } \\
71.7)\end{array}$ & $\begin{array}{l}93.3 \text { (87.2 to } \\
96.6)\end{array}$ \\
\hline & IFN- $\gamma$ & $116.1 \mathrm{ng} / \mathrm{L}$ & $\begin{array}{l}0.919^{*} \text { (0.856 to } \\
0.960 \text { ) }\end{array}$ & $\begin{array}{l}88.9 \text { (70.8 to } \\
97.6)\end{array}$ & $\begin{array}{l}94.9 \text { (88.4 to } \\
98.3)\end{array}$ & $\begin{array}{l}17.2(7.3 \text { to } \\
40.9)\end{array}$ & $\begin{array}{l}0.1 \text { (0 to } \\
0.3 \text { ) }\end{array}$ & $\begin{array}{l}82.8 \text { (66.9 to } \\
91.9)\end{array}$ & $\begin{array}{l}96.8 \text { (91.3 to } \\
98.9 \text { ) }\end{array}$ \\
\hline & IL-27 & $591.4 \mathrm{ng} / \mathrm{L}$ & $\begin{array}{l}0.976+(0.932 \text { to } \\
0.995)\end{array}$ & $\begin{array}{l}96.3 \text { (81.0 to } \\
99.9)\end{array}$ & $\begin{array}{l}99.0 \text { (94.4 to } \\
100.0)\end{array}$ & $\begin{array}{l}93.4(13.3 \text { to } \\
657.4)\end{array}$ & 0 (0 to 0.3$)$ & $\begin{array}{l}96.3 \text { (78.7 to } \\
99.5)\end{array}$ & $\begin{array}{l}99.0 \text { (93.3 to } \\
99.8)\end{array}$ \\
\hline
\end{tabular}

${ }^{*} \mathrm{p}<0.05,+\mathrm{p}<0.05$, compared with ADA using the $\mathrm{z}$ statistic, respectively. ADA adenosine deaminase; AUC area under the curve; IFN interferon; IL interleukin; NLR negative likelihood ratio; NPV negative predictive value; PLR positive likelihood ratio; PPV positive predictive value

$0.444]$ or IL-27 [0.003 ( -0.063 to 0.068$) ; \mathrm{z}=0.085 ; p=$ 0.932].

\section{Diagnostic accuracy of ADA, IFN- $\gamma$, and IL-27 in the Wuhan cohort}

For further validation of the diagnostic accuracy of ADA, IFN- $\gamma$, and IL-27 obtained from the Beijing cohort, we performed another prospective blinded study among the Wuhan cohort - a large urban city with high prevalence of tuberculosis (Table 4 and Fig. 2). In young patients, ADA, IFN- $\gamma$, and IL-27 were all perfect for diagnosing TPE $(p<0.001)$, presenting AUCs (95\% CIs) of 1.000 (0.832-1.000), 1.000 (0.832-1.000), and 1.000 (0.832-1.000), respectively, without significant differences. The AUCs in the Wuhan cohort were similar to the Beijing cohort (ADA: $\mathrm{T}=0, p=1.000$; IFN- $\gamma: \mathrm{T}=$ $0.014, p=0.906$; IL-27: $\mathrm{T}=0.700, p=0.403)$.

In older patients, excellent discrimination between TPE and non-TPE for IL-27 was observed [AUC: 0.976 (95\% CI: 0.924-0.996); $p<0.001$ ] (Table 4 and Fig. 2). The AUC of IL-27 was not higher than that of IFN- $\gamma$ [0.041 (-0.037 to $0.118 ; \mathrm{z}=1.024 ; p=0.306]$ but was significantly higher than that of ADA [0.131 (0.033$0.229) ; \mathrm{z}=2.623 ; p=0.009]$. Additionally, the AUC $(95 \%$ CI) of ADA was lower than that of IFN- $\gamma$ [0.091 (0.009$0.172) ; \mathrm{z}=2.168 ; p=0.030]$. The AUCs in the Wuhan cohort were similar to the Beijing cohort (ADA: T = $0.165, p=0.685$; IFN- $\gamma: \mathrm{T}=0.162, p=0.738$; IL-27: $\mathrm{T}=0$, $p=1.000)$.

The AUC (95\% CI) of ADA was significantly lower among older patients than young patients $[0.155$ (0.064-0.246]; $\mathrm{z}=3.338 ; \mathrm{p}<0.001]$ without significant differences for IFN- $\gamma[0.064(-0.003$ to 0.131$) ; \mathrm{z}=$ $1.886 ; p=0.059]$ or IL-27 [0.024 $(-0.017$ to 0.065$)$; $\mathrm{z}=1.148 ; p=0.251]$.
Thus, we confirmed that the diagnostic accuracies of the above three pleural biomarkers were similar in the two cohorts.

\section{Discussion}

Diagnosing pleural effusion remains a challenge in clinical practice. Considering different etiologies, tuberculosis is the most common cause of pleural effusion in developing countries [18, 19]. Unfortunately, conventional methods of microscopic examination, culture, or histopathological demonstration for diagnosing TPE have shown low sensitivity or are expensive and invasive $[2,20]$. A number of pleural soluble biomarkers have been evaluated $[5,12,19]$, yet a problem of insufficient overall diagnostic accuracy has consistently been encountered.

Several studies have introduced predictive models based on clinical parameters and the chemistry profile in pleural fluid to facilitate differential diagnosis between TPE and non-TPE [21], but few studies have looked into the factors affecting pleural biomarkers, especially in relation to age [6-11]. The majority of published studies are retrospective single-center ones and lack validation. In this post-hoc analysis of two independent prospective blinded studies, we evaluated the diagnostic values of ADA, IFN- $\gamma$, and IL-27 in pleural fluid for TPE according to different ages. Our results showed that the levels of these biomarkers were not different between young patients and older patients. In young patients, ADA, IFN- $\gamma$, and IL-27 accurately diagnosed TPE, while in older patients, IL-27 and IFN- $\gamma$ appeared as excellent options to discriminate TPE from non-TPE. Age affected the diagnostic accuracy of pleural ADA for TPE, with a trend towards a reduction in older patients. Of note, this is, to the best of our knowledge, the first study to examine factors affecting pleural IL-27. 


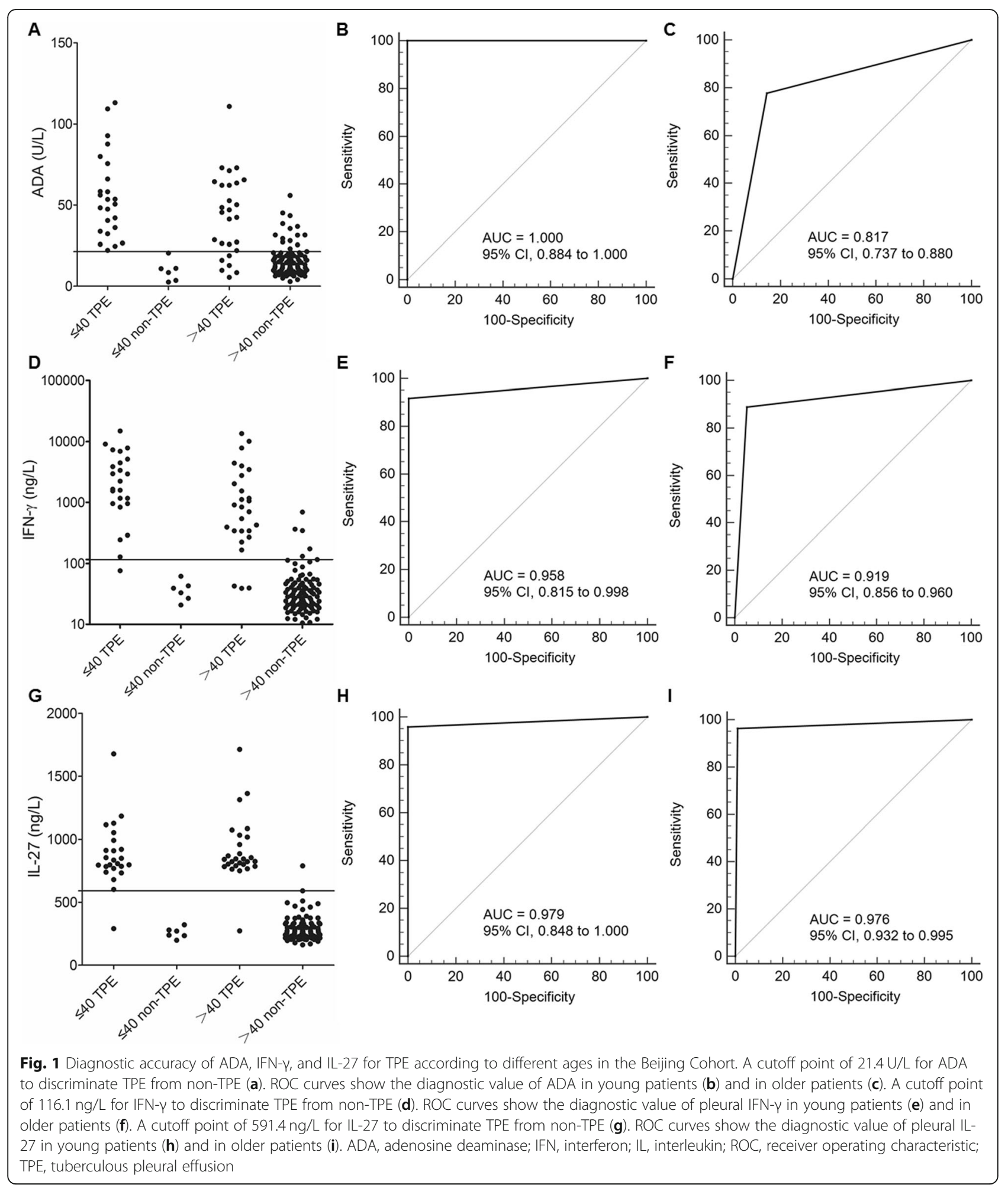

Several studies have demonstrated a negative correlation between pleural fluid ADA activity and age in the entire cohort and/or in a subgroup of patients with TPE [6-11], as age-associated immune decline is likely to affect ADA level. However, we did not find any difference between young patients and older patients regarding the concentrations of ADA, IFN- $\gamma$, and IL-27. This discrepancy may be partly related to the study inclusion criteria, the number of participants, and variations in age groups. Thus, the true role of age-associated 


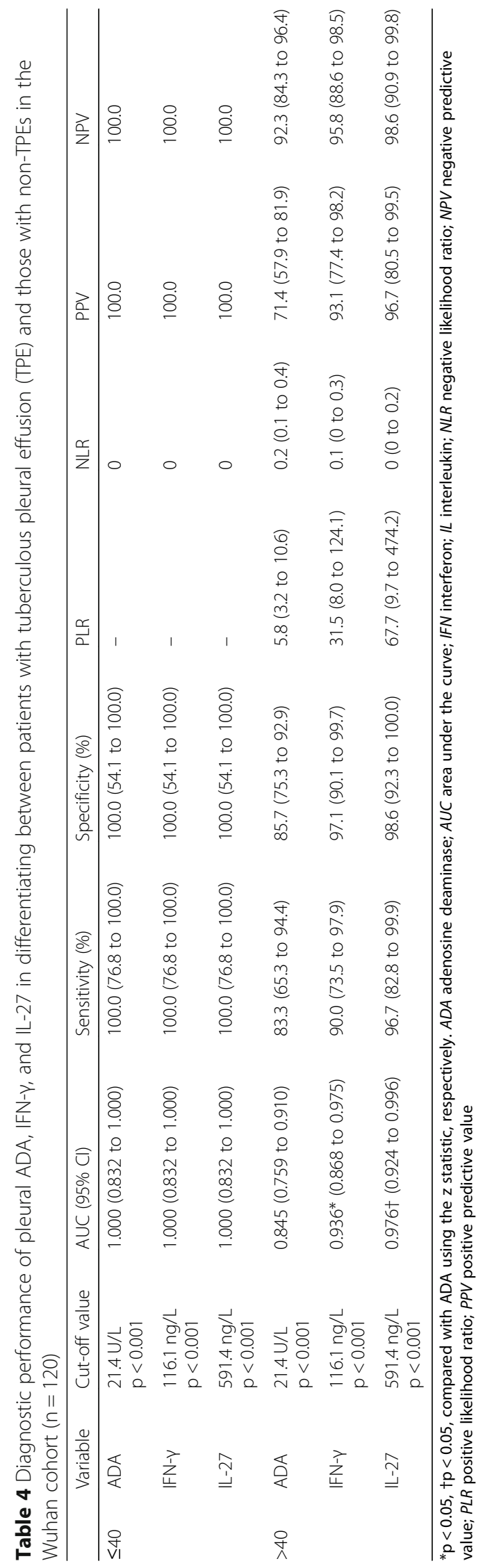




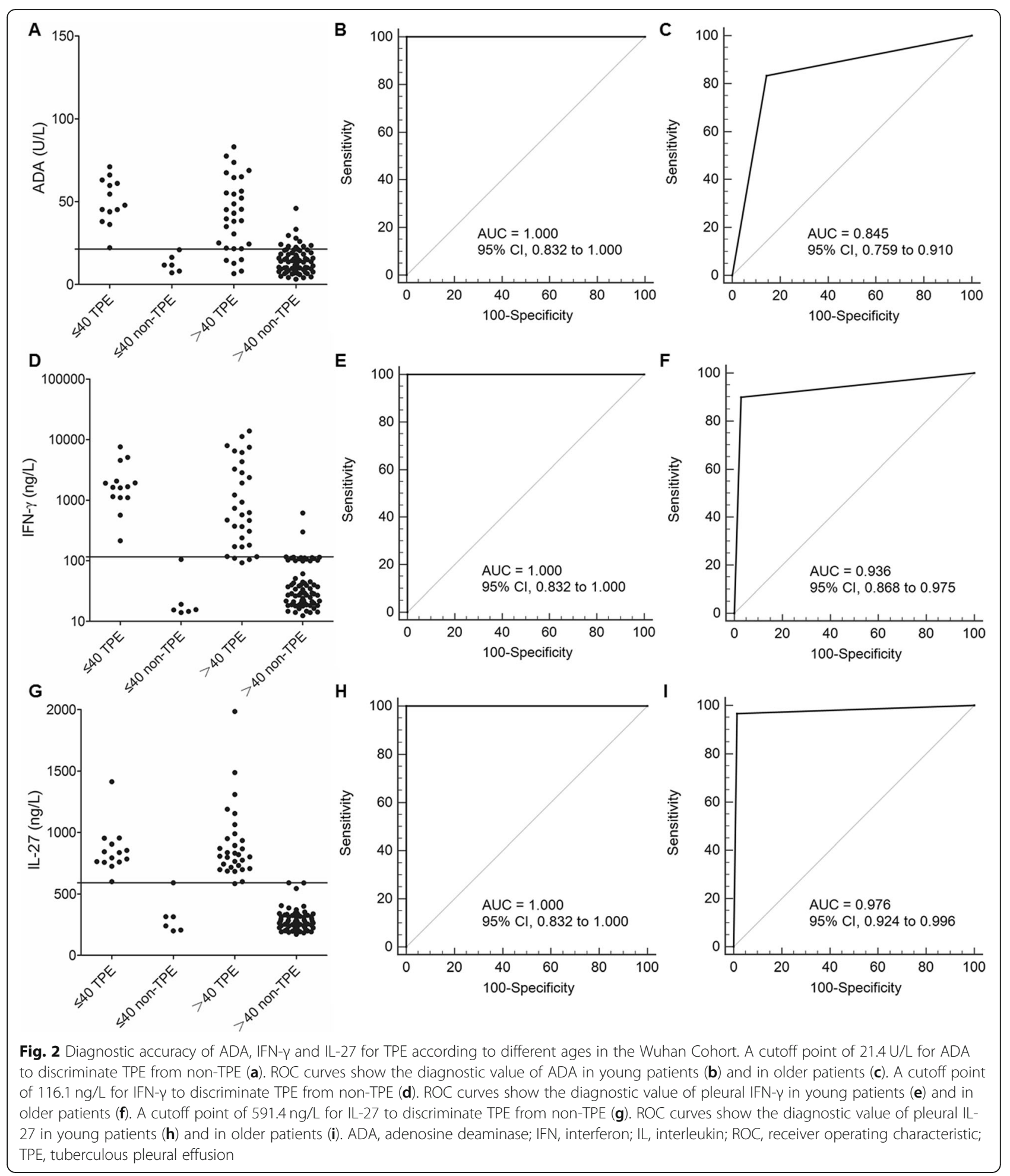

changes in pleural biomarker levels and the precise mechanisms remains an important area for future inquiry/investigation.

Several previous studies have reported relatively high diagnostic accuracy for pleural ADA, IFN- $\gamma$, and IL-27 for TPE $[12,22,23]$. One published study suggested that, in a region with a high prevalence of tuberculosis, the routine pleural fluid measurement of ADA concentration among young patients displays a reliable level of diagnostic accuracy [24]. Our research confirmed these earlier findings and further supports the use of ADA, IFN- $\gamma$, and IL-27 as excellent diagnostic biomarkers to 
discriminate TPE from non-TPE in young patients with high sensitivity and specificity values of 100.0 and $100.0 \%$, respectively. Each of these three biomarkers can be used as a rule-in test for TPE when they surpass their threshold values. TPE patients had a lower mean age, and tuberculosis was reported as the most common cause of pleural effusion in patients under 40 years of age in areas with a high incidence of tuberculosis [16], so the higher diagnostic accuracy of these biomarkers may partly be due to the increased prevalence of TPE. Some authors have also reported high ADA levels among patients with other causes of pleural effusion (e.g., pneumonia, empyema, lymphomas, adenocarcinomas, and systemic lupus erythematosus), but all of our young patients with these conditions showed pleural ADA concentrations below our diagnostic threshold. Most TPE cases could be diagnosed by medical thoracoscopy [25]; however, not everyone is a candidate for or willing to undergo thoracoscopy for its invasiveness. Since the detection of ADA is simpler and cheaper, the present study recommends it as the first choice for the diagnosis of TPE in young patients [26], may help to avoid further invasive biopsies in some cases.

IL-27, a member of the IL-12 cytokine family produced by activated antigen-presenting cells, has been reported to control the development of regulatory T cells and IL-17producing CD4+ T cells [27]. Our previous study showed that the diagnostic performance of IL-27 was comparable to that of IFN- $\gamma$ and more accurate than that of ADA in the diagnosis of TPE in the total patient population [12]. In the present study, we once again observed that, in both cohorts, IL-27 and IFN- $\gamma$ constitute excellent biomarkers to diagnose TPE in older patients and their diagnostic values are not affected by patient age. As the predictive value of pleural fluid ADA level for TPE decreases with increasing age, physicians should be cautious when interpreting the pleural ADA level to diagnose TPE if the patient is older. Some studies have suggested that the diagnostic cutoff value of pleural ADA activity for TPE requires adjustment according to different age groups $[6,8]$. Although IFN- $\gamma$ has an advantage in diagnosing TPE, its daily clinical use is limited due to the high cost and lack of acceptable cutoff value $[2,19]$. Due to the excellent diagnostic accuracy of pleural IL-27 for TPE in this study, such represents a potential option in routine clinical practice in older patients.

Based on the findings of our study, in regions of high tuberculosis prevalence, we hypothesize that combining pleural biomarkers with patients' age should be a simple method for estimating the probability of TPE with high sensitivity and specificity. If patients are younger than 40 years of age, we recommend testing for pleural ADA, while, if patients are older than 40 years of age, then IL27 should be measured. Due to the high diagnostic accuracy of pleural biomarkers according to different ages for TPE, one might consider skipping unnecessary invasive diagnostic procedures and initiating antituberculous therapy in certain groups of patients, and the study holds a certain meaning for health economics, especially in developing countries.

Several limitations of this study should not be ignored. First, although it provided data from two separate prospective cohorts containing more than 250 patients, the total number of cases was still small, especially in the young non-TPE group, as other causes of pleural effusion in young patients were relatively rare from the epidemiological perspective, and the small study sample may be affected by selection bias. Second, the prevalence of tuberculosis, time of pleural fluid collection, standardization of the detection method, or cutoff point may all influence the study results, and a subgroup analysis controlling for confounders was not conducted. Third, our simple flowchart, consisting of age and pleural biomarkers, is useful and accurate for TPE diagnosis. However, it is just a first step and should not be considered as an alternative to biopsy and culture. More invasive methods or other means should potentially follow to establish a definitive diagnosis of TPE. In addition, further studies are required to confirm the mechanism associated with the biomarkers in pleural fluids.

\section{Conclusions}

In conclusion, our study reports the use of pleural biomarkers according to different ages may improve the diagnostic accuracy for TPE. In high tuberculosis prevalence settings, in young patients, ADA, IFN- $\gamma$, and IL-27 could all accurately diagnosis TPE. In older patients, IL-27 and IFN- $\gamma$ are excellent biomarkers to discriminate TPE from non-TPE. However, additional studies are needed to provide more convincing data to establish the definite diagnosis of pleural effusion for clinical practice, especially before the results of biopsy or culture become available.

\section{Abbreviations}

ADA: Adenosine deaminase; ANOVA: Analysis of variance; AUC: Area under the curve; Cl: Confidence interval; IFN: Interferon; IL: Interleukin; MPE: Malignant pleural effusion; NLR: Negative likelihood ratio; NPV: Negative predictive value; PLR: Positive likelihood ratio; PPE: Parapneumonic pleural effusion; PPV: Positive predictive value; ROC: Receiver operating characteristic; TPE: Tuberculous pleural effusion

\section{Acknowledgements \\ The authors thank Dian-Bo Liu for his assistance in laboratory processing. The authors also thank physicians, nurses and patients for their participation in} the study.

\section{Authors' contributions}

CGJ, WW, QZ, XJW, ZW and KZ did patient recruitment and assessment, and performed study specimen preprocessing. CGJ, WW, XZW and KZ were

responsible for statistical analysis. CGJ, KZ and $\mathrm{HZS}$ interpreted the data and wrote the manuscript. All authors contributed to the subsequent drafts and approved the final version. HZS served as the guarantor of the paper, taking responsibility for the integrity of the work as a whole, from incepton to published article. 


\section{Funding}

This work was supported in part by grants from National Natural Science Foundation of China (No. 81970088, No. 81900093, No. 81900094, and No. 81400044) and in part by the Beijing Municipal Administration of Hospitals' Mission Plan (No. SML20150301). The funders had no role in the design of the study and collection, analysis, and interpretation of data and in writing the manuscript.

\section{Availability of data and materials}

The datasets used and/or analysed during the current study are available from the corresponding author on reasonable request.

\section{Ethics approval and consent to participate}

The study was approved by the ethics committees of Beijing Chaoyang Hospital, Capital Medical University, and Union Hospital, Tongji Medical College, Huazhong University of Science and Technology, China (No. 2012 S068, 2014-ke-63). All patients gave written informed consent for participation in the study.

\section{Consent for publication}

Not applicable.

\section{Competing interests}

The authors have declared that no conflict of interest exists.

\section{Author details}

${ }^{1}$ Department of Respiratory and Critical Care Medicine, Beijing Chaoyang Hospital, Capital Medical University, 8 Gongti Nanlu, Chaoyang District, Beijing 100020, China. ${ }^{2}$ Department of Respiratory and Critical Care Medicine, Union Hospital, Tongji Medical College, Huazhong University of Science and Technology, Wuhan, China.

Received: 14 February 2020 Accepted: 16 June 2020 Published online: 22 June 2020

\section{References}

1. Porcel JM. Tuberculous pleural effusion. Lung. 2009;187:263-70.

2. Light RW. Update on tuberculous pleural effusion. Respirology. 2010;15: 451-8.

3. Trajman A, Pai M, Dheda K, van Zyl SR, Zwerling AA, Joshi R, et al. Novel tests for diagnosing tuberculous pleural effusion: what works and what does not? Eur Respir J. 2008;31:1098-106.

4. Sahn SA, Huggins JT, San Jose ME, Alvarez-Dobano JM, Valdes L. Can tuberculous pleural effusions be diagnosed by pleural fluid analysis alone? Int J Tuberc Lung Dis. 2013;17:787-93.

5. Porcel JM. Biomarkers in the diagnosis of pleural diseases: a 2018 update. Ther Adv Respir Dis. 2018;12:1753466618808660.

6. Yeon KMKC, Kim JS, Kim CH. Influence of age on the adenosine deaminase activity in patients with exudative pleural effusion. Tuberculosis Respir Dis. 2002;53:530-41.

7. Zaric B, Kuruc V, Milovancev A, Markovic M, Sarcev T, Canak V, et al. Differential diagnosis of tuberculous and malignant pleural effusions: what is the role of adenosine deaminase? Lung. 2008;186:233-40.

8. Tay TR, Tee A. Factors affecting pleural fluid adenosine deaminase level and the implication on the diagnosis of tuberculous pleural effusion: a retrospective cohort study. BMC Infect Dis. 2013;13:546

9. Abrao FC, de Abreu IR, Miyake DH, Busico MA, Younes RN. Role of adenosine deaminase and the influence of age on the diagnosis of pleural tuberculosis. Int J Tuberc Lung Dis. 2014:18:1363-9.

10. Lee SJ, Kim HS, Lee SH, Lee TW, Lee HR, Cho YJ, et al. Factors influencing pleural adenosine deaminase level in patients with tuberculous pleurisy. Am J Med Sci. 2014;348:362-5.

11. Korczynski P, Klimiuk J, Safianowska A, Krenke R. Impact of age on the diagnostic yield of four different biomarkers of tuberculous pleural effusion. Tuberculosis (Edinb). 2019;114:24-9.

12. Wang W, Zhou Q, Zhai K, Wang Y, Liu JY, Wang XJ, et al. Diagnostic accuracy of interleukin 27 for tuberculous pleural effusion: two prospective studies and one meta-analysis. Thorax. 2018;73:240-7.

13. Hanley JA, McNeil BJ. A method of comparing the areas under receiver operating characteristic curves derived from the same cases. Radiology. 1983;148:839-43.
14. Hanley JA, McNeil BJ. The meaning and use of the area under a receiver operating characteristic (ROC) curve. Radiology. 1982:143:29-36.

15. Gönen M. Analyzing receiver operating characteristic curves with SAS. Cary: SAS Institute Inc.; 2007.

16. Villena V, López Encuentra A, Echave-Sustaeta J, Álvarez Martínez C, Martín EP. Estudio prospectivo de 1.000 pacientes consecutivos con derrame pleural. Etiología del derrame y características de los pacientes. Arch Bronconeumol. 2002;38:21-6.

17. Valdes L, San Jose ME, Pose A, Gude F, Gonzalez-Barcala FJ, Alvarez-Dobano $J M$, et al. Diagnosing tuberculous pleural effusion using clinical data and pleural fluid analysis a study of patients less than 40 years-old in an area with a high incidence of tuberculosis. Resp Med. 2010;104:1211-7.

18. Krenke R, Korczynski P. Use of pleural fluid levels of adenosine deaminase and interferon gamma in the diagnosis of tuberculous pleuritis. Curr Opin Pulm Med. 2010;16:367-75.

19. Skouras VS, Kalomenidis I. Pleural fluid tests to diagnose tuberculous pleuritis. Curr Opin Pulm Med. 2016:22:367-77.

20. Maturu VN, Dhooria S, Bal A, Singh N, Aggarwal AN, Gupta D, et al. Role of medical thoracoscopy and closed-blind pleural biopsy in undiagnosed exudative pleural effusions: a single-center experience of 348 patients. J Bronchol Interv Pulmonol. 2015;22:121-9.

21. Klimiuk J, Safianowska A, Chazan R, Korczynski P, Krenke R. Development and evaluation of the new predictive models in Tuberculous Pleuritis. Adv Exp Med Biol. 2015:873:53-63.

22. Jiang J, Shi HZ, Liang QL, Qin SM, Qin XJ. Diagnostic value of interferongamma in tuberculous pleurisy: a metaanalysis. Chest. 2007;131:1133-41.

23. Liang QL, Shi HZ, Wang K, Qin SM, Qin XJ. Diagnostic accuracy of adenosine deaminase in tuberculous pleurisy: a meta-analysis. Respir Med. 2008;102: 744-54.

24. Valdes L, Alvarez D, San Jose E, Juanatey JR, Pose A, Valle JM, et al. Value of adenosine deaminase in the diagnosis of tuberculous pleural effusions in young patients in a region of high prevalence of tuberculosis. Thorax. 1995; 50:600-3.

25. Wang Z, Xu LL, Wu YB, Wang XJ, Yang Y, Zhang J, et al. Diagnostic value and safety of medical thoracoscopy in tuberculous pleural effusion. Respir Med. 2015;109:1188-92.

26. Hooper C, Lee YCG, Maskell N. Investigation of a unilateral pleural effusion in adults: British Thoracic Society pleural disease guideline 2010. Thorax. 2010;65:ii4-ii17.

27. Wojno ED, Hosken N, Stumhofer JS, O'Hara AC, Mauldin E, Fang Q, et al. A role for IL-27 in limiting T regulatory cell populations. J Immunol. 2011;187: $266-73$

\section{Publisher's Note}

Springer Nature remains neutral with regard to jurisdictional claims in published maps and institutional affiliations.

Ready to submit your research? Choose BMC and benefit from

- fast, convenient online submission

- thorough peer review by experienced researchers in your field

- rapid publication on acceptance

- support for research data, including large and complex data types

- gold Open Access which fosters wider collaboration and increased citations

- maximum visibility for your research: over $100 \mathrm{M}$ website views per year

At BMC, research is always in progress.

Learn more biomedcentral.com/submission 